\title{
Association between vascular comorbidity and progression of Alzheimer's disease: a two-year observational study in Norwegian memory clinics
}

Rannveig Sakshaug Eldholm ${ }^{1,2^{*}}$, Karin Persson ${ }^{3,4}$, Maria Lage Barca ${ }^{3,4}$, Anne-Brita Knapskog ${ }^{4}$, Lena Cavallin ${ }^{5,6}$, Knut Engedal ${ }^{3,4}$, Geir Selbaek ${ }^{3,7,8}$, Eva Skovlund ${ }^{9}$ and Ingvild Saltvedt ${ }^{1,2}$

\begin{abstract}
Background: Vascular risk factors increase the risk of Alzheimer's disease (AD), but there is limited evidence on whether comorbid vascular conditions and risk factors have an impact on disease progression. The aim of this study was to examine the association between vascular disease and vascular risk factors and progression of AD.

Methods: In a longitudinal observational study in three Norwegian memory clinics, 282 AD patients (mean age 73. 3 years, 54\% female) were followed for mean 24 (16-37) months. Vascular risk factors and vascular diseases were registered at baseline, and the vascular burden was estimated by the Framingham Stroke Risk Profile (FSRP). Cerebral medical resonance images (MRIs) were assessed for white matter hyperintensities (WMH), lacunar and cortical infarcts. The associations between vascular comorbidity and progression of dementia as measured by annual change in Clinical Dementia Rating Sum of Boxes (CDR-SB) scores were analysed by multiple regression analyses, adjusted for age and sex.

Results: Hypertension occurred in 83\%, hypercholesterolemia in 53\%, diabetes in 9\%, 41\% were overweight, and 10\% were smokers. One third had a history of vascular disease; $16 \%$ had heart disease and 15\% had experienced a cerebrovascular event. MRI showed lacunar infarcts in 16\%, WMH with Fazekas score 2 in 26\%, and Fazekas score 3 in $33 \%$. Neither the vascular risk factors and diseases, the FSRP score, nor cerebrovascular disease was associated with disease progression in AD.
\end{abstract}

Conclusions: Although vascular risk factors and vascular diseases were prevalent, no impact on the progression of AD after 2 years was shown.

Keywords: Alzheimer's disease, Dementia, Mild cognitive impairment, Vascular risk factors, Cardiovascular disease, Cardiovascular risk, Cognitive decline, Progression, Prognosis

\section{Background}

Longitudinal studies have established a strong link between vascular risk factors in midlife, such as hypertension, hypercholesterolemia, diabetes mellitus, smoking and being overweight, and development of Alzheimer's disease (AD) decades later [1]. The mechanisms by

\footnotetext{
* Correspondence: rannveig.s.eldholm@ntnu.no

${ }^{1}$ Department of Neuromedicine and Movement Science, Faculty of Medicine and Health Sciences, Norwegian University of Science and Technology (NTNU), 7491 Trondheim, Norway

${ }^{2}$ Department of Geriatrics, St. Olavs Hospital, Trondheim University Hospital, Trondheim, Norway

Full list of author information is available at the end of the article
}

which vascular risk factors influence the risk of $\mathrm{AD}$ are not entirely understood. Both in vivo and postmortem studies have shown an association between vascular risk factors and amyloid deposition in the brain [2, 3]. Chronic hypertension affects the blood-brain barrier and may alter the clearance of amyloid $\beta(\mathrm{A} \beta)$ [4]. Cerebral blood flow is regulated according to neuronal demands by the neurovascular unit, consisting of microvessels, astrocytes, neurons, and supporting cells that have close anatomical and chemical connections. Reduced cerebral blood flow and dysfunction of the neurovascular unit appear to be key pathways for neuronal damage [5]. In

(c) The Author(s). 2018 Open Access This article is distributed under the terms of the Creative Commons Attribution 4.0 International License (http://creativecommons.org/licenses/by/4.0/), which permits unrestricted use, distribution, and reproduction in any medium, provided you give appropriate credit to the original author(s) and the source, provide a link to the Creative Commons license, and indicate if changes were made. The Creative Commons Public Domain Dedication waiver (http://creativecommons.org/publicdomain/zero/1.0/) applies to the data made available in this article, unless otherwise stated. 
addition, inflammation may be of importance by causing cerebral atrophy and cognitive decline $[6,7]$. It is suggested that $\mathrm{AD}$ pathology accumulates for many years or even decades before symptoms evolve [8]. However, it is not known if, or to what extent, the presence of vascular risk factors in late life leads to accumulation of AD pathology, as a recent study found no association between late-life vascular risk factors and late-life brain amyloid deposition [2].

As the association between midlife vascular risk factors and incident $\mathrm{AD}$ is well established, it could be hypothesised that these risk factors also affect progression after symptoms evolve. A systematic review suggested an association between LDL cholesterol and progression of $\mathrm{AD}$ [9], but this has not been a consistent finding in later studies [10-14]. The literature is conflicting regarding which vascular risk factors could be of significance for progression, and even whether these factors seem to ameliorate or aggravate the disease course.

Cerebrovascular diseases are frequent in $\mathrm{AD}$ patients, and most elderly $\mathrm{AD}$ patients show comorbid brain pathologies in addition to amyloid. In a brain autopsy study with 4629 AD patients, 32\% had cerebrovascular disease with a severity that could contribute to their cognitive status while $48 \%$ had minor vascular pathology [15]. The threshold at which AD becomes symptomatic is lowered by cerebrovascular disease, and $\mathrm{AD}$ pathology is a significant contributor to post-stroke dementia $[16,17]$. However, it is not clear whether cerebrovascular disease accelerates disease progression in AD. Although one study showed that white matter intensities (WMH) might exacerbate disease progression in AD dementia [18], most studies on conversion from mild cognitive impairment (MCI) to AD dementia have failed to show that WMH or lacunes are of importance [19].

Extra-cerebral vascular diseases are also associated with cognitive impairment and dementia. Atrial fibrillation $(\mathrm{AF})$ and generalised atherosclerosis increase the risk of cognitive impairment or dementia, and myocardial infarction, peripheral artery disease and congestive heart failure may also be of importance $[1,20]$. It may be hypothesised that comorbid cardiovascular disorders increase $\mathrm{AD}$ progression through various pathogenetic mechanisms. The consequence of impaired cardiac output may be diminished cerebral blood flow that could increase $A \beta$ generation and reduce clearance of $A \beta$. Another possible mechanism is neuroinflammation, as chronic systemic inflammation has been shown in AF, heart failure and atherosclerosis [21-23]. Further, an elevated level of inflammation in midlife is associated with smaller brain volume and reduced episodic memory in late life [7]. However, there are few studies on the association between cardiovascular diseases and progression of $\mathrm{AD}$. One study found that $\mathrm{AF}$ and angina pectoris were associated with a more rapid decline in cognitive performance, while a history of coronary artery bypass graft surgery was associated with a slower deterioration in $\mathrm{AD}$ [24].

Based on the studies mentioned above, it is likely that the total vascular burden, including vascular risk factors and cardiovascular and cerebrovascular disorders, exerts a cumulative effect on the progression of AD. Previous studies have shown an association between composite cardiovascular risk scores in midlife and cognitive decline and incident dementia in late life [25]. However, the relationship between total vascular burden and disease progression in $\mathrm{AD}$ patients is less studied [24, 26, 27].

In the Progression of Alzheimer's Disease and Resource use (PADR) study, we have previously reported considerable heterogeneity in the 2-year progression rate of $\mathrm{AD}$. Increased evidence on predictors of progression in $\mathrm{AD}$ is important for individual patients, their families and society, and could even have therapeutic consequences, as these are modifiable and potential targets for intervention. The aim of the study is to investigate whether single vascular risk factors and diseases and total vascular burden are predictors of progression in $\mathrm{AD}$.

\section{Methods \\ Patients}

The Progression of Alzheimer's Disease and Resource Use (PADR) study is a descriptive, longitudinal study conducted in three Norwegian memory clinics, with recruitment of patients between 2009 and 2014. Included were patients with dementia or MCI at baseline, who were home-dwelling, were able to give informed consent and had a proxy who could serve as an informant. Patients who were not fluent in Norwegian, had severe physical illness or lived far away from the memory clinics were excluded.

Patients underwent baseline assessments at the time of diagnostic workup and a follow-up assessment after a mean of 24 months (range 16-37, 80\% between 20 and 28 months). The present study included 177 patients with a diagnosis of AD dementia and 105 patients with amnestic MCI (aMCI). The criteria established by the National Institute of Neurological and Communicative Disorders and Stroke-Alzheimer's Disease and Related Disorders Association (NINCDS-ADRDA) were used for $\mathrm{AD}$ dementia [28]. The Winblad criteria were used to diagnose MCI [29]. MCI patients with impaired memory as an early symptom and a score equivalent to or below $-1.5 \mathrm{SD}$ on at least one memory test were categorised as aMCI [30]. The aMCI group was considered to have $\mathrm{AD}$ (without dementia). The diagnostic measures of the PADR study and disease progression of the AD patients have been described previously [31].

The study was conducted according to the Helsinki declaration, participation was voluntary, and patients 
received oral and written information and gave written consent to participate. Only patients with capacity to consent at baseline were recruited. The Regional Committee for Medical and Health Research Ethics in South East Norway approved the study.

\section{Assessments}

Patients underwent comprehensive neuropsychological and physical examinations at baseline, according to a standardised research manual, with most of the tests repeated at follow-up. The evaluation also included measurements of height, weight, systolic and diastolic blood pressure, and in most cases an electrocardiogram (ECG). Demographic data, medical history, smoking status and drugs in current use were recorded. The cognitive test battery included the Mini-Mental State Examination (MMSE) (0-30) [32]. The primary outcome measure was the Clinical Dementia Rating scale Sum of Boxes (CDR$\mathrm{SB})$. The CDR evaluates six areas of cognition and function and assesses the severity of impairment on the range from normal cognitive function to severe dementia. Each of six items is scored $0-3$ and item scores can be summed to produce a continuous scale, CDR-SB $(0-18$, higher scores denoting more severe impairment) [33].

Blood sample analyses included cholesterol, creatinine and glucose. Estimated glomerular filtration rate (eGFR) was calculated based on serum or plasma creatinine using the Chronic Kidney Disease Epidemiology Collaboration (CKD-EPI) equation. Apolipoprotein E (ApoE) genotyping was conducted using the Illumina Infinium OmniExpress v1.1 chip at deCODE Genetics, Reykjavik, Iceland, and the result was dichotomised based on the presence of at least one ApoE epsilon 4 (ApoE \&4) allele into carriers and non-carriers of ApoE $\varepsilon 4$. Structural brain imaging was performed for all patients at baseline, using magnetic resonance imaging (MRI) in most cases (87\%); however, some patients underwent computed tomography (CT) scans because of pacemakers or claustrophobia.

\section{Vascular risk factors}

Patients were considered as having hypertension when reported in their medical history, if using antihypertensives (angiotensin-converting enzyme inhibitors, angiotensin II receptor antagonists, beta blockers, diuretics or calcium antagonists), or if they had a blood pressure of $>140$ systolic or $>90$ diastolic at baseline. Patients had hypercholesterolemia if this was reported in the medical history, they used statins or had a total cholesterol level of $\geq 6.5 \mathrm{mmol} / \mathrm{l}$ at baseline. Diabetes was registered by medical history or the use of any antidiabetic drug. Being overweight was defined as having a body mass index $\geq 25 \mathrm{~kg} / \mathrm{m}^{2}$, and patients were registered as smokers if they smoked at baseline, regardless of former smoking history. AF was recorded from the medical history and ECGs. Information on previous strokes, transient ischemic attacks, heart disease (angina pectoris, myocardial infarction, heart failure or valvular disease), and peripheral artery disease was retrieved from the hospitals' medical records.

To assess the vascular burden of each patient, the Framingham Stroke Risk Profile (FSRP) was calculated. The score integrates the effect of age, sex, and measurements of systolic blood pressure, the use of antihypertensive treatment, diabetes mellitus, current smoking status, prevalent cardiovascular disease, current or previous $\mathrm{AF}$, and the presence or absence of left ventricular hypertrophy on ECG. Cardiovascular disease is defined in this risk score as a history of myocardial infarction, angina pectoris, intermittent claudication or congestive heart failure. ECGs were examined for left ventricular hypertrophy according to the Framingham criteria [34]. In addition to the original FSRP, risk scores for all patients were calculated with the recently published revised FSRP, based on more current data on stroke risk factors, with a lower impact of AF and prevalent cardiovascular disease [35].

Blood pressure measurements were missing for three, smoking status for seven, weight and height for 26 , creatinine for ten, cholesterol measurements for 48 , and an ECG for 71 patients. When measurements were not available, vascular risk factor status was based on medical history and drug use alone.

\section{MRI scans}

An experienced neuroradiologist examined the MRI scans blinded to all clinical data. Medial temporal atrophy (MTA) was rated using the Scheltens MTA scale [36], which includes evaluation of the choroid fissure, the temporal horn of the lateral ventricle, and the height of the hippocampus, yielding a score of 0-4 (higher score denoting more atrophy). MTA was assessed on the left and right sides separately, and the mean score was calculated. WMHs were evaluated using the Fazekas scale, rating severity of WMHs in the periventricular and subcortical regions combined on a scale of $0-3$ [37]. The presence and number of lacunes $(\leq 10 \mathrm{~mm})$ and cortical infarcts were recorded.

The MRI examinations were regular clinical examinations conducted at several different centres using different MRI protocols. Only MRIs performed within 6 months before or after the clinical assessment at baseline were included for analyses (mean 2.3 months (SD 1.5), within < 4 months in $88 \%$ of participants), resulting in MRIs from 206 AD patients.

\section{Statistics}

Descriptive statistical methods were used for baseline characteristics. For comparisons between groups, 
independent samples t-tests were used for continuous data, and Pearson's $x^{2}$ test was used for categorical data. Change from baseline to follow-up was calculated by dividing CDR-SB score differences by time in years. Follow-up time was checked for normal distribution.

Linear regression analyses were conducted with the progression as measured by annual CDR-SB change as the dependent variable. First, unadjusted analyses were carried out for vascular risk factors, vascular diseases, FSRP and MRI findings. Interactions between vascular factors and ApoE \&4 carrier status and disease stage (MCI or dementia) were explored and were not significant. All analyses except FSRP were then adjusted for age and sex. Subgroup analyses were performed on patients found to have hypertension, hypercholesterolemia or diabetes that was not treated at baseline, in order to investigate the potential effect of untreated risk factors on the progression of AD.

Data were analysed using IBM SPSS Statistics for Windows, version 24.0, Armonk, NY, USA. Statistical significance was defined as $p<0.05$.

\section{Results}

The mean age of the study patients was 73.3 (SD 8.8) years, $54 \%$ were women, $61 \%$ were apoE $\varepsilon 4$ carriers, and the mean MMSE score was 23.7 (SD 4.4) (Table 1). In the study sample, $83 \%$ had hypertension, $53 \%$ hypercholesterolemia, $9 \%$ diabetes, $41 \%$ were overweight and $10 \%$ smokers. Only $6 \%$ had none of these vascular risk factors, whereas $24 \%$ had one, $45 \%$ two, $20 \%$ three, $5 \%$ had four, and none had all five of them. A history of vascular disease was present in $33 \%$ of the patients, the most common being heart disease (16\%) and cerebrovascular events (15\%). On MRI, 16\% had lacunar and $4 \%$ had cortical infarcts. WMHs with a Fazekas score of 2 were present in 26, and 33\% had WMHs with a Fazekas score of 3.

Unadjusted regression analyses showed no significant associations between any individual vascular risk factor and progression of $\mathrm{AD}$ (not shown). There was a trend for patients with high BMI to progress less than others $(p=0.09)$, and the same trend was found for patients with three or more vascular risk factors $(p=0.16)$. Results adjusted for age and sex are shown in Table 2 . There was no significant association between the FSRP score and progression of AD (Table 2). The revised FSRP score gave significantly lower stroke risk estimates for both men and women and did not show any significant association with $\mathrm{AD}$ progression (not shown). The existence of cerebrovascular disease on MRI, as infarcts (either cortical or lacunar) or WMHs, was not found to predict progression of AD.

Regression analyses were additionally performed on subgroups of patients with untreated hypertension,
Table 1 Clinical and demographic characteristics at baseline

\begin{tabular}{llll}
\hline & Total & & \\
\hline Age, years, mean (SD) & 282 & 73.3 & $(8.8)$ \\
Female, n (\%) & 282 & 153 & $(54.3)$ \\
Education, years, mean (SD) & 282 & 11.7 & $(3.6)$ \\
Drugs in regular use, mean (SD) & 280 & 3.1 & $(2.6)$ \\
$\quad$ Antihypertensives, number of users (\%) & 280 & 137 & $(48.9)$ \\
Statins, number of users (\%) & 280 & 85 & $(14.7)$ \\
Antidiabetic agents (number of users, \%) & 280 & 20 & $(7.1)$ \\
Antithrombotic agents (number of users, \%) & 280 & 131 & $(46.8)$ \\
$\quad$ Platelet inhibitors (number of users, \%) & 280 & 114 & $(40.4)$ \\
$\quad$ Anticoagulants (number of users, \%) & 280 & 21 & $(7.5)$ \\
ApoE $\varepsilon 4$ carrier, n (\%) & 252 & 154 & $(61.1)$ \\
MMSE (0-30), mean (SD) & 280 & 23.7 & $(4.4)$ \\
CDR sum of boxes (0-18), mean (SD) & 282 & 4.2 & $(2.8)$ \\
Vascular risk factors (VRFs) & & & \\
Hypertension, n (\%) & 282 & 234 & $(83.0)$ \\
Hypercholesterolemia, n (\%) & 282 & 149 & $(52.8)$ \\
Diabetes mellitus, n (\%) & 282 & 26 & $(9.2)$ \\
Overweight (BMI > 25), n (\%) & 256 & 106 & $(41.4)$ \\
Smoking (current), n (\%) & 275 & 26 & $(9.5)$ \\
Framingham Stroke Risk Profile ${ }^{\text {b }}$ (0-1), & 113 & 0.21 & $(0.14)$ \\
women, mean (SD) & & & \\
Framingham Stroke Risk Profile ${ }^{\mathrm{b}}$ (0-1), & 9.26 & $(0.16)$
\end{tabular}

men, mean (SD)

Vascular diseases

Atrial fibrillation, $\mathrm{n}(\%)$

History of cerebrovascular event

(stroke or TIA), n (\%)

History of heart disease, $\mathrm{n}(\%)$

Left ventricular hypertrophy in $\mathrm{ECG}^{\mathrm{a}}, \mathrm{n}(\%)$

History of peripheral vascular disease, $\mathrm{n}(\%)$

Estimated GFR $<60 \mathrm{ml} / \mathrm{min} / 1.73 \mathrm{~m}^{2}, \mathrm{n}(\%)$

$\begin{array}{lll}282 & 28 & (9.9) \\ 282 & 43 & (15.2) \\ 282 & 46 & (16.3) \\ 211 & 8 & (3.8) \\ 273 & 7 & (2.6) \\ 273 & 47 & (17.2)\end{array}$

MRI findings

Medial temporal lobe atrophy

(mean of both sides), mean (SD)

Cortical infarcts, n (\%)

Lacunar infarcts, $\mathrm{n}(\%)$

$203 \quad 1.9$

$(0.9)$

$\begin{array}{lll}206 & 9 & (4.4)\end{array}$

White matter hyperintensities

Fazekas 0 or 1, n (\%)

$206 \quad 33$

(16.0)

Fazekas 2, n (\%)

$205 \quad 84$

(40.9)

Fazekas 3, n (\%)

$205 \quad 53$

(25.9)

$205 \quad 68 \quad(33.2)$

Cerebrovascular disease: cortical infarcts, $\quad 206 \quad 128 \quad$ (62.1) lacunes or Fazekas $\geq 2, n$

Cerebrovascular disease: cortical infarcts, lacunes or Fazekas 3, n

${ }^{a}$ Framingham criteria

${ }^{\mathrm{b}}$ Ten year probability of stroke 
Table 2 Associations between vascular risk factors at baseline and progression measured by annual change in CDR-SB

\begin{tabular}{|c|c|c|c|c|}
\hline & \multicolumn{4}{|c|}{ Age and sex-adjusted } \\
\hline & Beta & $95 \% \mathrm{Cl}$ & $p$ & $R^{2}$ \\
\hline \multicolumn{5}{|l|}{ Vascular risk factors (VRFs) } \\
\hline Hypertension & -0.049 & $(-0.617,0.519)$ & 0.87 & 0.04 \\
\hline Hypercholesterolemia & 0.262 & $(-0.153,0.676)$ & 0.22 & 0.05 \\
\hline Diabetes mellitus & 0.128 & $(-0.592,0.848)$ & 0.73 & 0.04 \\
\hline Overweight (BMI $\geq 25$ ) & -0.391 & $(-0.840,0.059)$ & 0.09 & 0.04 \\
\hline Smoking (current) & 0.050 & $(-0.677,0.778)$ & 0.89 & 0.04 \\
\hline$\geq 2$ VRFs & 0.121 & $(-0.370,0.612)$ & 0.63 & 0.03 \\
\hline$\geq 3$ VRFs & -0.371 & $(-0.889,0.147)$ & 0.16 & 0.04 \\
\hline Framingham Stroke Risk Profile, women* & -0.297 & $(-2.769,2.175)$ & 0.81 & 0.00 \\
\hline Framingham Stroke Risk Profile, men* & 0.930 & $(-1.638,3498)$ & 0.47 & 0.01 \\
\hline ApoE $\varepsilon 4$ carrier & 0.384 & $(-0.069,0.836)$ & 0.10 & 0.06 \\
\hline \multicolumn{5}{|l|}{ Vascular diseases } \\
\hline Heart disease & 0.196 & $(-0.380,0.771)$ & 0.50 & 0.04 \\
\hline Atrial fibrillation & -0.159 & $(0.902,0.583)$ & 0.67 & 0.04 \\
\hline Peripheral vascular disease & 0.512 & $(-0.834,1.858)$ & 0.46 & 0.04 \\
\hline Cerebrovascular event (stroke and/or TIA) & -0.315 & $(-0.896,0.265)$ & 0.29 & 0.04 \\
\hline \multicolumn{5}{|l|}{ MRI findings } \\
\hline Cortical infarcts ( $1=$ cortical infarcts, $0=$ no cortical infarcts $)$ & 0.707 & $(-0.518,1.932)$ & 0.26 & 0.04 \\
\hline Lacunes ( $1=\geq 1$ lacune on MRI, $0=$ no lacunes) & -0.177 & $(-0.867,0.514)$ & 0.61 & 0.04 \\
\hline Infarcts (cortical and/or lacunes) & 0.038 & $(-0.611,0.687)$ & 0.91 & 0.03 \\
\hline White matter hyperintensities Fazekas 3 & -0.291 & $(-0.872,0.290)$ & 0.32 & 0.04 \\
\hline White matter hyperintensities Fazekas 2 or 3 & -0.207 & $(-0.776,0.362)$ & 0.47 & 0.04 \\
\hline Infarcts and/or WMH Fazekas 3 & -0.079 & $(-0.625,0.468)$ & 0.78 & 0.03 \\
\hline Infarcts and/or WMH Fazekas 2 or 3 & -0.298 & $(-0.872,0.277)$ & 0.31 & 0.04 \\
\hline MTA (mean of right and left side) & 0.036 & $(-0.262,0.334)$ & 0.81 & 0.04 \\
\hline
\end{tabular}

* The Framingham Stroke Risk Profiles were not adjusted for age and sex

hypercholesterolemia or diabetes, but no association with the progression of AD was found (not shown).

\section{Discussion}

In this descriptive cohort study in memory clinic patients with $\mathrm{AD}$, we examined whether vascular risk factors, cardiovascular and cerebrovascular diseases or total vascular burden were of importance for the progression of AD. None of these was shown to predict progression of AD. Prevalence of vascular risk factors and vascular diseases was high in the study population, and many patients received treatment for these disorders at baseline.

Given the strong link between vascular risk factors in midlife and later development of $\mathrm{AD}$, the lack of association between late-life vascular burden and disease progression in $\mathrm{AD}$ is surprising. Although single risk factors might not have sufficient power to determine AD progression, we would have expected a combination of risk factors or diseases to show an effect. However, as no consistent effect of any vascular risk factor has been identified across studies, it is possible that vascular risk factors do not influence the progression of $\mathrm{AD}$ in the symptomatic stage $[10,14]$. The time lag between midlife exposure to vascular risk factors and development of $\mathrm{AD}$ may be several decades. If the effect of vascular risk factors is mediated through slowly evolving processes, as amyloid accumulation and development of WMHs, the time may be too short to observe a difference from vascular risk factors in late life [2]. An alternative explanation may be that when the amount of AD pathology surpasses a certain threshold, as may be the case for many patients with $\mathrm{AD}$ dementia, the influence of $\mathrm{AD}$ pathology may be so strong that an additional effect of vascular disease cannot be discerned [38, 39].

Contrary to our hypothesis, we observed a trend for slower disease progression in the patients with the highest number of vascular risk factors. It is possible that this group will have more vascular pathology, contributing to the initial diagnosis and severity of cognitive impairment or dementia, but to a lower burden of $\mathrm{AD}$ 
pathology. This may explain an apparent protective effect of vascular risk factors on cognitive decline. Alternatively, successful treatment of vascular risk factors may have influenced the disease course.

Although obesity is considered a cardiovascular risk factor, in the present study, we found a trend for patients with high BMI to progress less than patients of normal weight. This has been observed in other studies and may be a result of reverse causality [40].

Despite the high prevalence of cerebrovascular disease among study patients, we were not able to demonstrate any association between MRI findings of cerebrovascular disease and progression of $\mathrm{AD}$. As we know that the coexistence of cerebrovascular disease lowers the symptomatic threshold of $\mathrm{AD}$ [17], our hypothesis was that these patients would experience a more rapid progression. However, this may not be the case, as they may have developed cognitive impairment with less underlying $\mathrm{AD}$ pathology than others. Longitudinal studies indicate that the reduction in cognitive function associated with cerebrovascular injury remains relatively stable over time in old age, whereas the $\mathrm{AD}$ pathology leads to increasing impairment [41].

As only half of the study patients showed more than minimal progression over 2 years [31], our study may have lacked sufficient power to show an effect of vascular burden. If the impact of vascular burden emerges very gradually, e.g. as a result of amyloid accumulating slowly, the follow-up time of 2 years may be too short. We did not find an association between untreated risk factors and progression of cognitive decline. However, many of our patients received treatment for their vascular risk factors at baseline, and the negative findings may be a consequence of optimal treatment.

Another explanation for the lack of associations in the present study may be related to characteristics of the study population, who were memory clinic patients, younger, more educated and with milder $\mathrm{AD}$ than the general $\mathrm{AD}$ population. We have previously shown that the overall progression rate of $\mathrm{AD}$ patients in the PADR study was similar to what has been reported in other studies [31]. The prevalence of vascular risk factors and diseases increases with age, as does the proportion of $\mathrm{AD}$ patients who have comorbid vascular brain pathology. Seven percent of the study patients died before follow-up; some of them may have died of vascular disease.

Vascular risk factors and diseases were frequent in the study sample and comparable to other studies [11, 13]. In comparison with elderly participants in a Norwegian population study [42], the prevalence of diabetes and hypercholesterolemia was similar, while hypertension, coronary artery disease and strokes were more common among our study patients. On the other hand, fewer of our patients were overweight or smoked. Despite the high prevalence of hypertension in our study, there were few cases of left ventricular hypertrophy and low numbers of chronic kidney disease (Table 2), indicating successful antihypertensive treatment. The frequency of ApoE $\varepsilon 4$ carriers was similar to other studies in AD patients [43]. Thus, we found no differences in vascular burden between our study and other AD studies that could explain the lack of association between vascular burden and progression of AD among our patients.

It can be questioned whether the FSRP represents a good proxy measure of vascular burden for our study. The FSRP evaluates only the current levels of risk factors and does not take into account previous risk levels or vascular disease in the brain. Because several vascular risk factors tend to decrease in the years leading up to dementia [44], the FSRP score may not give optimal risk estimates when used in the memory clinic.

The inclusion criteria and the attrition rate limit the generalisability of the study. Although patients lost to follow-up did not differ in comorbidities compared to the patients who remained in the study, the prevalence of smokers was twice as high in this group. We may have missed unrecognised type 2 diabetes as a risk factor, as we did not screen for this. The MRI for the study was performed as clinical procedures, not standardised for research, and was not repeated at follow-up. Thus, analyses on progression in relation to change in MRI findings could not be conducted. Although we recorded the medical history of all patients, information regarding duration and timing of risk factors was seldom available.

\section{Conclusion}

The present study found no association between vascular risk factors and cerebrovascular disease and progression of AD. Further clinical studies with larger sample sizes and longer follow-up are needed to clarify whether vascular conditions may influence disease progression in AD. The clinical question remains if and how we should treat $\mathrm{AD}$ patients with vascular risk factors to prevent disease progression, and future studies are needed to answer this.

\section{Abbreviations}

AD: Alzheimer's disease; ApoE ع4: Apolipoprotein E epsilon 4; ApoE: Apolipoprotein E; CKD-EPI: Chronic Kidney Disease Epidemiology Collaboration; CDR: Clinical Dementia Rating Scale; CDR-SB: Clinical Dementia Rating scale Sum of Boxes; CT: Computer tomography;

ECG: Electrocardiogram; FSRP: Framingham Stroke Risk Profile; ICD-

10: International Classification of Diseases 10th revision; MCl: Mild cognitive impairment; MMSE: Mini-Mental State Examination; MRI: Magnetic resonance imaging; NINCDS-ADRDA: National Institute of Neurological Disorders and Stroke-Alzheimer Disease and Related Disorders; PADR: Progression of Alzheimer's Disease and Resource use; REC: Regional Committees for Medical and Health Research Ethics; SD: Standard deviation; VRF: Vascular risk factor; WMH: White matter hyperintensities 


\section{Acknowledgements}

We thank the study participants, their caregivers and the employees of the nursing homes for their contributions to the study. We also thank the staff in the three memory clinics in St. Olavs Hospital, Oslo University Hospital and Innlandet Hospital for their willingness and collaboration, and the Norwegian register for persons with cognitive symptoms (NorCog) for their contribution to the study.

\section{Funding}

The work by Rannveig S. Eldholm and Maria L. Barca was funded from the Norwegian ExtraFoundation for Health and Rehabilitation through the Norwegian Health Association. Rannveig S. Eldholm also received funding from the Liaison Committee between the Central Norway Regional Health Authority and the Norwegian University of Science and Technology (NTNU). Karin Persson's work was funded by the Southern and Eastern Norway Regional Health Authority.

\section{Availability of data and materials}

The baseline data from patients assessed at Oslo University Hospital and at Innlandet Hospital Trust are available in "The Norwegian Register for persons with cognitive symptoms" (NorCog), but restrictions apply to the availability of these data, which were used under license for the current study, and so are not publicly available. Data are however available from the authors upon reasonable request and with permission from the Norwegian National Advisory Unit on Ageing and Health and Norwegian University of Science and Technology (NTNU).

\section{Authors' contributions}

IS and RSE designed the study. RSE, MLB and KP assessed the patients, and RSE, MLB, KP, IS and KE contributed in diagnosing the patients. LC examined and rated the MRI scans. RSE, IS and ES analysed the data and RSE, IS, ES, KP, $M L B, K E, A B K$ and GS interpreted the results. RSE drafted the manuscript, and RSE, KP, MLB, ABK, KE, GS, ES and IS contributed in writing and revising the manuscript. All authors read and approved the final manuscript.

\section{Ethics approval and consent to participate}

The Regional Committee for Medical and Health Research Ethics for South East Norway approved the study (REC number 2011/531). Patients underwent comprehensive cognitive testing at baseline, and only those who were found to have sufficient cognitive capacity to provide their own consent were invited to participate in the study. All patients gave written, informed consent for their participation in the study and for their clinical data to be used for research purposes. Patients who were not able to give informed consent at baseline were not included.

\section{Competing interests}

The authors declare that they have no competing interests.

\section{Publisher's Note}

Springer Nature remains neutral with regard to jurisdictional claims in published maps and institutional affiliations.

\section{Author details}

'Department of Neuromedicine and Movement Science, Faculty of Medicine and Health Sciences, Norwegian University of Science and Technology (NTNU), 7491 Trondheim, Norway. ${ }^{2}$ Department of Geriatrics, St. Olavs Hospital, Trondheim University Hospital, Trondheim, Norway. ${ }^{3}$ Norwegian National Advisory Unit on Ageing and Health, Vestfold Hospital Trust, Tønsberg, Norway. ${ }^{4}$ Department of Geriatric Medicine, Memory Clinic, Oslo University Hospital, Ullevaal, Oslo, Norway. ${ }^{5}$ Department of Clinical Science, Intervention, and Technology, Division of Medical Imaging and Technology, Karolinska Institute, Stockholm, Sweden. ${ }^{6}$ Department of Radiology, Karolinska University Hospital, Stockholm, Sweden. ${ }^{7}$ Centre for Old Age Psychiatric Research, Innlandet Hospital Trust, Ottestad, Norway. ${ }^{8}$ Institute of Health and Society, University of Oslo, Oslo, Norway. ${ }^{9}$ Department of Public Health and Nursing, Norwegian University of Science and Technology (NTNU), Trondheim, Norway.
Received: 29 December 2017 Accepted: 9 May 2018

Published online: 22 May 2018

\section{References}

1. Livingston G, Sommerlad A, Orgeta V, Costafreda SG, Huntley J, Ames D, Ballard C, Banerjee S, Burns A, Cohen-Mansfield J, et al. Dementia prevention, intervention, and care. Lancet. 2017;

2. Gottesman RF, Schneider AL, Zhou Y, Coresh J, Green E, Gupta N, Knopman DS, Mintz A, Rahmim A, Sharrett AR, et al. Association between midlife vascular risk factors and estimated brain amyloid deposition. JAMA. 2017; 317(14):1443-50.

3. Petrovitch H, White LR, Izmirilian G, Ross GW, Havlik RJ, Markesbery W, Nelson J, Davis DG, Hardman J, Foley DJ, et al. Midlife blood pressure and neuritic plaques, neurofibrillary tangles, and brain weight at death: the HAAS. Honolulu-Asia aging Study. Neurobiol Aging. 2000;21(1):57-62.

4. Kruyer A, Soplop N, Strickland S, Norris EH. Chronic hypertension leads to Neurodegeneration in the TgSwDI mouse model of Alzheimer's disease. Hypertension. 2015;66(1):175-82.

5. Roher AE, Debbins JP, Malek-Ahmadi M, Chen K, Pipe JG, Maze S, Belden C, Maarouf $\mathrm{CL}$, Thiyyagura P, Mo H, et al. Cerebral blood flow in Alzheimer's disease. Vasc Health Risk Manag. 2012;8(1):599-611.

6. Economos A, Wright CB, Moon YP, Rundek T, Rabbani L, Paik MC, Sacco RL, Elkind MS. Interleukin 6 plasma concentration associates with cognitive decline: the northern Manhattan study. Neuroepidemiology. 2013;40(4):253-9.

7. Walker KA, Hoogeveen RC, Folsom AR, Ballantyne CM, Knopman DS, Windham BG, Jack CR Jr, Gottesman RF. Midlife systemic inflammatory markers are associated with late-life brain volume: the ARIC study. Neurology. 2017:89(22):2262-70.

8. Jansen WJ, Ossenkoppele R, Knol DL, Tijms BM, Scheltens P, Verhey FR, Visser PJ, Amyloid Biomarker Study G, Aalten P, Aarsland D, et al. Prevalence of cerebral amyloid pathology in persons without dementia: a metaanalysis. JAMA. 2015;313(19):1924-38.

9. Blom K, Emmelot-Vonk MH, Koek HL. The influence of vascular risk factors on cognitive decline in patients with dementia: a systematic review. Maturitas. 2013;76(2):113-7.

10. Li J, Cesari M, Liu F, Dong B, Vellas B. Effects of diabetes mellitus on cognitive decline in patients with Alzheimer disease: a systematic review. Can J Diabetes. 2017;41(1):114-9.

11. Bergland AK, Dalen I, Larsen Al, Aarsland D, Soennesyn H. Effect of vascular risk factors on the progression of mild Alzheimer's disease and Lewy body dementia. J Alzheimers Dis. 2017;56(2):575-84.

12. Qiao J, Lu WH, Wang J, Guo XJ, Qu QM. Vascular risk factors aggravate the progression of Alzheimer's disease: a 3-year follow-up study of Chinese population. Am J Alzheimers Dis Other Demen. 2014;29(6):521-5.

13. Blom K, Vaartjes I, Peters SA, Koek HL. The influence of vascular risk factors on cognitive decline in patients with Alzheimer's disease. Maturitas. 2014; 79(1):96-9.

14. Bos I, Vos SJ, Frölich L, Kornhuber J, Wiltfang J, Maier W, Peters O, Rüther E, Engelborghs $\mathrm{S}$, Niemantsverdriet $\mathrm{E}$, et al. The frequency and influence of dementia risk factors in prodromal Alzheimer's disease. Neurobiol Aging. 2017;56:33-40

15. Toledo JB, Arnold SE, Raible K, Brettschneider J, Xie SX, Grossman M, Monsell SE, Kukull WA, Trojanowski JQ. Contribution of cerebrovascular disease in autopsy confirmed neurodegenerative disease cases in the National Alzheimer's coordinating Centre. Brain. 2013;136(Pt 9):2697-706.

16. Mok VC, Lam BY, Wong A, Ko H, Markus HS, Wong LK. Early-onset and delayed-onset poststroke dementia - revisiting the mechanisms. Nat Rev Neurol. 2017;13(3):148-59.

17. White LR, Edland SD, Hemmy LS, Montine KS, Zarow C, Sonnen JA, UyeharaLock JH, Gelber RP, Ross GW, Petrovitch H, et al. Neuropathologic comorbidity and cognitive impairment in the Nun and Honolulu-Asia aging studies. Neurology. 2016;86(11):1000-8.

18. Brickman AM. Contemplating Alzheimer's disease and the contribution of white matter hyperintensities. Curr Neurol Neurosci Rep. 2013;13(12):415.

19. Prins ND, van der Flier WM, Brashear HR, Knol DL, van de Pol LA, Barkhof F, Scheltens P. Predictors of progression from mild cognitive impairment to dementia in the placebo-arm of a clinical trial population. J Alzheimers Dis. 2013;36(1):79-85.

20. Stefanidis KB, Askew CD, Greaves K, Summers MJ. The effect of non-stroke cardiovascular disease states on risk for cognitive decline and dementia: a systematic and meta-analytic review. Neuropsychol Rev. 2017; 
21. Crandall MA, Horne BD, Day JD, Anderson JL, Muhlestein JB, Crandall BG, Weiss JP, Lappe DL, Bunch TJ. Atrial fibrillation and CHADS2 risk factors are associated with highly sensitive C-reactive protein incrementally and independently. Pacing Clin Electrophysiol. 2009;32(5):648-52.

22. Rajendiran KS, Ananthanarayanan RH, Satheesh S, Rajappa M. Elevated levels of serum sialic acid and high-sensitivity C-reactive protein: markers of systemic inflammation in patients with chronic heart failure. Br J Biomed Sci. 2014;71(1):29-32.

23. Libby P. Inflammation in atherosclerosis. Arterioscler Thromb Vasc Biol. 2012; 32(9):2045-51.

24. Mielke MM, Rosenberg PB, Tschanz J, Cook L, Corcoran C, Hayden KM, Norton M, Rabins PV, Green RC, Welsh-Bohmer KA, et al. Vascular factors predict rate of progression in Alzheimer disease. Neurology. 2007;69(19):1850-8.

25. Harrison SL, Ding J, Tang EY, Siervo M, Robinson L, Jagger C, Stephan BC. Cardiovascular disease risk models and longitudinal changes in cognition: a systematic review. PLoS One. 2014;9(12):e114431.

26. Viticchi G, Falsetti L, Buratti L, Boria C, Luzzi S, Bartolini M, Provinciali L, Silvestrini M. Framingham risk score can predict cognitive decline progression in Alzheimer's disease. Neurobiol Aging. 2015;36(11):2940-5.

27. Viticchi G, Falsetti L, Buratti L, Sajeva G, Luzzi S, Bartolini M, Provinciali L, Silvestrini M. Framingham risk score and the risk of progression from mild cognitive impairment to dementia. J Alzheimers Dis. 2017;59(1):67-75.

28. McKhann G, Drachman D, Folstein M, Katzman R, Price D, Stadlan EM. Clinical diagnosis of Alzheimer's disease: report of the NINCDS-ADRDA work group under the auspices of Department of Health and Human Services Task Force on Alzheimer's disease. Neurology. 1984;34(7):939-44.

29. Winblad B, Palmer K, Kivipelto M, Jelic V, Fratiglioni L, Wahlund LO, Nordberg A, Backman L, Albert M, Almkvist O, et al. Mild cognitive impairment-beyond controversies, towards a consensus: report of the international working group on mild cognitive impairment. J Intern Med. 2004;256(3):240-6.

30. Petersen R, Smith G, Waring S, Ivnik R, Tangalos E, Kokmen E. Mild cognitive impairment: clinical characterization and outcome. Arch Neurol. 1999;56(3):303-8.

31. Eldholm RS, Barca ML, Persson K, Knapskog AB, Kersten H, Engedal K, Selbaek G, Braekhus A, Skovlund E, Saltvedt I. Progression of Alzheimer's disease: a longitudinal study in Norwegian memory clinics. J Alzheimers Dis. 2018;61(3):1221-32

32. Folstein MF, Folstein SE, McHugh PR. "Mini-mental state". A practical method for grading the cognitive state of patients for the clinician. J Psychiatr Res. 1975;12(3):189-98.

33. Morris JC. The clinical dementia rating (CDR): current version and scoring rules. Neurology. 1993;43(11):2412-4.

34. Levy D, Labib SB, Anderson KM, Christiansen JC, Kannel WB, Castelli WP. Determinants of sensitivity and specificity of electrocardiographic criteria for left ventricular hypertrophy. Circulation. 1990;81(3):815-20.

35. Dufouil C, Beiser A, McLure LA, Wolf PA, Tzourio C, Howard VJ, Westwood AJ, Himali JJ, Sullivan L, Aparicio HJ, et al. Revised Framingham stroke risk profile to reflect temporal trends. Circulation. 2017;135(12):1145-59.

36. Scheltens $P$, Leys D, Barkhof F, Huglo D, Weinstein HC, Vermersch $P$, Kuiper M, Steinling M, Wolters EC, Valk J. Atrophy of medial temporal lobes on MRI in "probable" Alzheimer's disease and normal ageing: diagnostic value and neuropsychological correlates. J Neurol Neurosurg Psychiatry. 1992;55(10):967-72.

37. Pantoni L, Basile AM, Pracucci G, Asplund K, Bogousslavsky J, Chabriat $H$, Erkinjuntti T, Fazekas F, Ferro JM, Hennerici M, et al. Impact of agerelated cerebral white matter changes on the transition to disability the LADIS study: rationale, design and methodology. Neuroepidemiology. 2005;24(1-2):51-62.

38. Chui HC, Zarow C, Mack WJ, Ellis WG, Zheng L, Jagust WJ, Mungas D, Reed BR, Kramer JH, Decarli CC, et al. Cognitive impact of subcortical vascular and Alzheimer's disease pathology. Ann Neurol. 2006;60(6):677-87.

39. Jellinger KA, Attems J. Prevalence and impact of cerebrovascular pathology in Alzheimer's disease and parkinsonism. Acta Neurol Scand. 2006;114(1):38-46.

40. Nordestgaard LT, Tybjærg-Hansen A, Nordestgaard BG, Frikke-Schmidt R. Body mass index and risk of Alzheimer's disease: a mendelian randomization study of 399,536 individuals. J Clin Endocrinol Metab. 2017; 102(7):2310-20

41. Boyle PA, Yang J, Yu L, Leurgans SE, Capuano AW, Schneider JA, Wilson RS, Bennett DA. Varied effects of age-related neuropathologies on the trajectory of late life cognitive decline. Brain. 2017;140(3):804-12.
42. Krokstad SK, Skjei M. Public health development. The HUNT study, Norway. HUNT 1 (1984-86) - HUNT2 (1995-97) - HUNT 3 (2006-08). In: HUNT research center. Levanger: HUNT research center; 2011. p. 213.

43. Sando SB, Melquist S, Cannon A, Hutton ML, Sletvold O, Saltvedt I, White LR, Lydersen S, Aasly JO. APOE epsilon 4 lowers age at onset and is a high risk factor for Alzheimer's disease; a case control study from Central Norway. BMC Neurol. 2008:8:9.

44. Winblad B, Amouyel P, Andrieu S, Ballard C, Brayne C, Brodaty H, CedazoMinguez A, Dubois B, Edvardsson D, Feldman H, et al. Defeating Alzheimer's disease and other dementias: a priority for European science and society. Lancet Neurol. 2016;15(5):455-532.

\section{Ready to submit your research? Choose BMC and benefit from:}

- fast, convenient online submission

- thorough peer review by experienced researchers in your field

- rapid publication on acceptance

- support for research data, including large and complex data types

- gold Open Access which fosters wider collaboration and increased citations

- maximum visibility for your research: over $100 \mathrm{M}$ website views per year

At BMC, research is always in progress.

Learn more biomedcentral.com/submissions 